\title{
Gaza Strip
}

National Cancer Institute

\section{Source}

National Cancer Institute. Gaza Strip. NCI Thesaurus. Code C123754.

360 square kilometers in the Middle East, bordering the Mediterranean Sea, between Egypt and Israel. 